\title{
Detrital Influence on Neodymium Isotope Record of the Last Deglaciation in the North Atlantic
}

\author{
APRIL N ABBOTT ${ }^{1}$ STEFAN LÖHR $^{2}$ ANNABEL PAYNE ${ }^{3}$ \\ HANNAH KUMAR ${ }^{4}$ \\ ${ }^{1}$ Department of Earth and Environmental Sciences, \\ Macquarie University, abbot152@d.umn.edu \\ ${ }^{2}$ Department of Earth and Environmental Sciences, \\ Macquarie University, Stefan.Loehr@mq.edu.au \\ ${ }^{3}$ Institute of Geosciences, Chritian-Albrachts- Universität zu \\ Kiel,BellaCPayne@gmail.com \\ ${ }^{4}$ Department of Earth and Environmental Sciences, \\ Macquarie University, Hannah.Kumar@hdr.mq.edu.au
}

Sediment-water interactions during early diagenesis have a significant potential to influence authigenic paleoclimate records. The recently proposed sedimentary source of rare earth elements to the ocean suggests that the paleocirculation signal reconstructed from authigenic neodymium isotope records may be compromised by sediment-water exchange processes during early diagenesis. Here, we examine the potential overprinting of a seawater signature in North Atlantic sediments since the Last Glacial Maximum, approximately $22 \mathrm{ka}$ ago. Specifically, we present authigenic and bulk sediment neodymium isotope data for International Ocean Drilling Program sites 1063 and 1308. The Last Glacial Maximum and the subsequent deglaciation marks a period of abrupt climate change and catastrophic collapse of Northern Hemisphere ice sheets accompanied by massive reorganisations and speed variations in the Atlantic Meridional Overturning Circulation. Over this time period, we demonstrate changes in the authigenic neodymium isotope signature are concurrent with changes in sediment provenance and sediment composition. We evaluate the possibility that the authigenic record is not an independent water mass tracer during this interval, and propose that our new data demonstrates that the authigenic neodymium isotope record is influenced by changes in sediment characteristics at both ODP site 1063 and IODP site 1308. This finding supports a diagenetic overprinting of the seawater signature in the authigenic phases by the pore water but does not entirely preclude the use of neodymium proxy records. Instead, we propose that the authigenic neodymium isotope record can reveal information about changes in circulation and changes in sedimentation when coupled with total sediment composition and provenance. 